\title{
Accuracy Check and Comparative Analysis of Horizontal Fiber- Optic Gyro Inclinometer in Freezing Hole
}

\author{
JIANG Guojing ${ }^{1,2}$, LI Fangzheng ${ }^{2}$, ZHOU Xiaomin ${ }^{1}$, GAO Wei ${ }^{2}$, CUI Bingbing ${ }^{2}$ \\ ${ }^{1}$ University of Science and Technology Beijing, Beijing 100083, China; \\ ${ }^{2}$ Beijing China Coal Mine Engineering Co., Ltd., Beijng 100013, China)
}

\begin{abstract}
Based on the principle of fiber-optic gyro inclinometer, the characteristics of horizontal freezing hole and the working conditions, it is analyzed that the horizontal hole fiber-optic gyroscope tilting technology for freezing holes is one of the most reliable methods. In order to verify the azimuth measurement error of the horizontal fiber optic-gyro inclinometer, the simulation test under the 1:1 working condition was carried out with the actual working conditions on site. Compared with the total station measurement data, it was concluded that $85.2 \%$ of the data is in measurement error within $\pm 2^{\circ}, 55.6 \%$ of the data is within $\pm 1^{\circ}$, which verifies the reliability of the measurement data of the horizontal fiber-optic gyro inclinometer. At the test level of $\alpha=0.05$, the azimuth test error accords with the normal distribution of $\mu=0.54$ and $\sigma=0.73$. In the actual use process, the algorithm can be used to optimize the measurement data by taking multiple measurements and taking the average value in combination with the field conditions, so that the data can be closer to the true value.
\end{abstract}

\section{Introduction}

The urban underground space development is a great undertaking that "benefits both the present and future generations". Driven by the metro construction, the $21^{\text {st }}$ century has witnessed the era of underground space development ${ }^{[1-3]}$. Since the freezing method is introduced into the municipal engineering construction, it has become one of the main construction methods to reinforce caving ground with its unique advantages (high strength, good water sealing performance, flexibility, etc.) ${ }^{[4-5]}$. Since the horizontal ground freezing technology is developed in China in 1997, the freezing method has been widely applied to metro connecting passages and departure and reception of shield engineering ${ }^{[6]}$. The core technical issue of the freezing method is to solve the problem of "two walls with one drill" and ensuring the drill hole quality is the first step to the success of the freezing method. Over the past 20 years, in connecting passages and departure and reception of shield reinforcing engineering to which the freezing method of the municipal engineering is applied, due to the small hole spacing (generally less than $20 \mathrm{~m}$ ), after the freezing pipe is put in place, the traditional method of incline-measure by light can be basically used to effectively determine the hole deflection. Thus, the method of incline-measure by light has become an important and reliable means to test the hole quality ${ }^{[7]}$.

In recent years, as the rail transit overlapping projects have sprung up in first-tier cities, the crossing freezing project starts to take shape ${ }^{[8]}$. As the freezing method is applied to areas which develop in the direction of depth in the municipal engineering and the spacing of the horizontal drilling is constantly growing, the method of incline-measure by light has been unable to meet the needs of long-distance drilling. In addition, freezing pipes are generally made of seamless steel, its incline-measure environment is complicated, which is mainly the magnetic environment, and it can also be affected by the vibration of drills during construction. Therefore, the research on a high-precision means for detecting the hole deflection in magnetic and harsh conditions becomes the key to ensuring the hole quality.

\section{The Status of the horizontal incline-measure technology}

The traditional drilling inline-measure method which is mainly the magnetic method, means to calculate the deflection azimuth angle according to changes of the included angle between the sensitive shaft of the measuring instrument and the geomagnetic field. The current measuring element of the azimuth angle is mainly the fluxgate. When the instrument is disturbed by the external magnetic field, its accuracy will decline or it even cannot work at all. As a result, the magnetic method could not apply to the freezing pipe in the magnetic environment. In order to determine the azimuth without relying on the geomagnetic field, the first method is to

Email: 414495497@qq.com 
use the principle of relative measurement of azimuth, that is, to align a given direction on the ground, and record the angles of the instrument's rotation and its revolution along the drilling hole track as the instrument goes down the well. This method is adopted by the traditional framework-based mechanical gyros [9]. But the framework-based mechanical gyro inclinometer has complex structures and it is very difficult to process and debug. Since the gyro element is in a high-speed rotating state, it can be easily affected by the vibration. Factors including the rotating torque caused by gravity after the gyro's mass center deviates from the support center and the rotation of the earth may all lead to azimuthal measurement error of the instrument. For working conditions where the freezing hole is susceptible to vibrations, it is not fit for mechanical gyros. The second method is the three-dimensional coordinate method. At present, the mainstream trenchless pipeline detection equipment in China is mostly $\mathrm{ABM}$ series and DR series products manufactured by Belgium Reduct company. This series of pipeline detection systems have the advantages of high reliability, simple operation and durability. By calculating changes in $X$ direction (distance), Y direction (heading), $\mathrm{Z}$ direction (pitching) and scroll position of each point, the three-dimensional data coordinate of a pipeline is finally obtained. Given the coordinate value of input points and output points, the three-dimensional coordinate of a pipeline can be reduced to the three-dimensional coordinate of the pipeline under the construction coordinate system or the urban coordinate system ${ }^{9}$. The inclinometer in the freezing pipe is a blind hole and only the coordinate value of the input point is known, so the use of this instrument is limited.

The fiber-optical gyro inclinometer adopts the method of measuring the angular velocity of rotation of the earth to determine the bearing of drilling. It does not rely on the geomagnetic field so it can overcome the interference of the magnetic field. Besides, its light solid structure makes it have the advantage of strong seismic resistance. Therefore, the research on the use of horizontal fiber-optical gyro incline-measure technology is the first choice for the quality inspection of long-distance freezing holes and drilling holes.

\section{Instrument principles and indicators $^{12}$}

The rationale of fiber-optical gyro inclinometers is Sagnac Effect of light. Sagnac Effect refers to a general effect that the beam of light travels within a closed loop which rotates in the relative inertial space, that is, two beams of light with equal features from the same light source in the closed loop travel in the opposite direction and finally converge to the same detection point. When there is an angular velocity $\Omega$ of rotation around the axis perpendicular to the surface of the closed loop in the relative inertial space, the optical path difference will be generated as the beams of light travel in two opposite optical paths. The optical path difference is proportional to the angular velocity $\Omega$ of rotation.

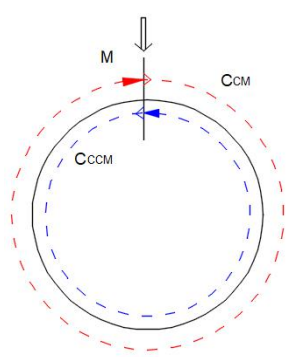

(a) (b)

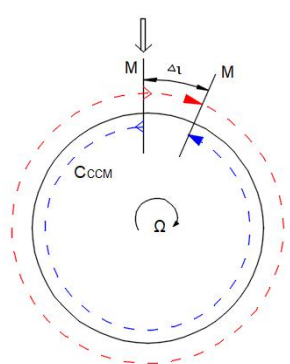

Fig.1 Sagnac effect of light

$\Delta \theta=\varpi \Delta t=2 \pi \Omega L D / c \lambda$

Among them, $\mathrm{L}$ is the optical fiber length, $\mathrm{D}$ is the fiber diameter, $\lambda$ is the optical wavelength of light source, $\mathrm{c}$ is the velocity of light transmission in a vacuum. For the fiber-optical gyro inclinometer whose optical fiber length is constant, when the wavelength of light source is given, the formula above can determine the one-to-one correspondence between $\Delta \theta$ and $\Omega$.

In order to meet the needs of long-distance horizontal freezing incline-measure, based on the current fiber-optical gyro incline-measure technology, the first horizontal fiber-optical gyro inclinometer for the freezing hole in China was developed. Its technical indicators are as shown in Table 1:

Table1 Horizontal fiber optic gyroscope inclinometer parameters for freezing holes

\begin{tabular}{|c|c|c|c|c|}
\hline name & weight/kg & $\begin{array}{c}\text { External } \\
\text { diameter/cm }\end{array}$ & length/mm & $\begin{array}{c}\text { Azimuth } \\
\text { accuracy/ }\end{array}$ \\
\hline $\begin{array}{c}\text { Horizontal fiber } \\
\text { optic gyro } \\
\text { inclinometer }\end{array}$ & 10 & 40 & 1950 & \pm 2 \\
\hline
\end{tabular}

\subsection{Experimental scheme}

The inertial measurement system is the core of fiber-optical gyro inclinometers, which includes three accelerometers and a gyroscope. In order to test the actual measurement accuracy of horizontal azimuth angles of fiber-optical gyros, the field test is carried out combined with the horizontal crossing drilling project at Guoquan road of Shanghai rail transit. In the crossing freezing project at Guoquan road, the horizontal drilling length is $42 \mathrm{~m}$, the horizontal hole opening angle is in the range of $0 \sim 2.66^{\circ}$, and the vertical hole opening angle is in the range of $0 \sim 1.5^{\circ}$. Based on the actual drilling track, the experimental scheme is designed to test the accuracy of the azimuth angle of the horizontal fiber-optical gyro inclinometer applied to the freezing hole.

Table2 Design of Accuracy Checking Scheme for Horizontal Fiber Optic Gyro Inclinometer

\begin{tabular}{|c|c|c|c|c|c|}
\hline number & $\begin{array}{l}\text { Length } \\
\text { of } \\
\text { freezing } \\
\text { pipe } / \mathrm{m}\end{array}$ & $\begin{array}{c}\text { Layout } \\
\text { vertical } \\
\text { angle/ }{ }^{\circ}\end{array}$ & $\begin{array}{c}\text { Layout } \\
\text { horizontal } \\
\text { angle }^{\circ}\end{array}$ & $\begin{array}{c}\text { Vertical } \\
\text { deflection } \\
\text { of final } \\
\text { hole/mm }\end{array}$ & $\begin{array}{c}\text { Horizontal } \\
\text { deflection } \\
\text { of final } \\
\text { hole } / \mathrm{mm} \\
\end{array}$ \\
\hline 1 & 40 & 0.5 & -2.66 & -220 & -480 \\
\hline \multicolumn{6}{|c|}{$\begin{array}{l}\text { remarks: horizontal angle (the left is "-", the right is"+") ; vertical angle: } \\
\text { (up for "+", down for"-") }\end{array}$} \\
\hline
\end{tabular}


The freezing pipe used in the experiment is made of $\Phi 108 * 10$ seamless steel pipe, each of which is 2 meters long. It is connected with screw threads and established according to the experiment scheme with the U-shaped support welded as the base.

The gyro moves at constant speed by traction in the freezing pipe. Sampling points are taken every 4 meters, and there are totally 10 sampling points for each test.

At the same time, the total station measurement method is used to measure the azimuth angle of each measuring point and the result is compared and analyzed with the measurement data of the horizontal fiber-optical gyro inclinometer.

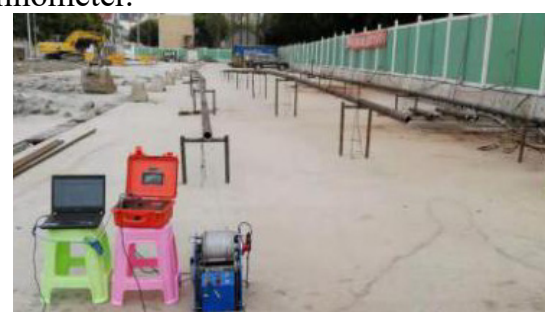

Fig.2 Horizontal fiber optic gyroscope inclinometer test

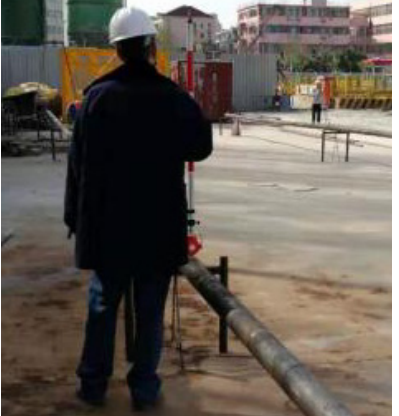

Fig.3 Total station measurement check

\section{Comparative analysis of experimental results}

The verification of the azimuth angle of the horizontal fiber-optical gyro inclinometer is mainly to compare the design accuracy with repeated measurement results, so as to determine the reliability of the accuracy. According to the actual situation, the comparative analysis of azimuth test results is shown in Table 3.

Table3 Comparative Analysis of Azimuth Measurement of Horizontal Fiber Optic Gyro Inclinometer and Total Station Measurement Data

\begin{tabular}{|c|c|c|c|c|c|c|c|c|}
\hline $\begin{array}{l}\text { Upward } \\
\text { angle }\end{array}$ & length $/ \mathrm{m}$ & Test $11^{\circ}$ & Test $2{ }^{\circ}$ & Test $3 /^{\circ}$ & $\begin{array}{l}\text { Total station } \\
\text { measurement } /{ }^{\circ}\end{array}$ & deviation $1{ }^{\circ}$ & Deviation $2 /^{\circ}$ & deviation $3 /^{\circ}$ \\
\hline \multirow{10}{*}{$0.5^{\circ}$} & 39 & 116.6 & 116.4 & 114.9 & 113.9 & 2.7 & 2.5 & 1.0 \\
\hline & 35 & 113.9 & 112.8 & 114.4 & 113.3 & 0.6 & -0.5 & 1.1 \\
\hline & 31 & 113.1 & 114.4 & 115.1 & 113.8 & -0.7 & 0.6 & 1.3 \\
\hline & 27 & 114.4 & 110.7 & 115.9 & 114.3 & 0.1 & -3.6 & 1.6 \\
\hline & 23 & 115.1 & 115.6 & & 114.4 & 0.7 & 1.2 & \\
\hline & 19 & 115.4 & 114.8 & 114.8 & 114.5 & 0.9 & 0.3 & 0.3 \\
\hline & 15 & 117 & 114.9 & & 114.6 & 2.4 & 0.3 & \\
\hline & 11 & 116.2 & 115.9 & & 114.9 & 1.3 & 1.0 & \\
\hline & 7 & 115.9 & 114.9 & 115.4 & 115.0 & 0.9 & -0.1 & 0.4 \\
\hline & 3 & 116.7 & 115.4 & 113.9 & 115.3 & 1.4 & 0.1 & -1.4 \\
\hline
\end{tabular}

According to the analysis of 27 groups of comparative data of azimuthal measurement, the measurement error of $85.2 \%$ of the data is within the range of $\pm 2^{\circ}$, and that of $55.6 \%$ of the data is within the range of $\pm 1^{\circ}$.

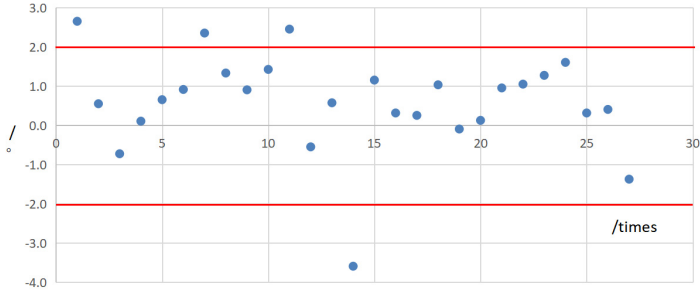

Table4 Discrete graph of measurement error data

\section{Normal distribution analysis of experimental error data}

\subsection{Normal verification}

With four groups of singular points beyond the accuracy range of the instrument eliminated, and the residual data of measurement errors as variables, the normal verification is conducted by using statistical analysis software to calculate skewness, kurtosis and the corresponding standard deviation.

Table4 Normality test statistical analysis table with skewness and peak value

\begin{tabular}{|c|c|c|c|}
\hline number & project & statistac & Z-score \\
\hline 1 & skewness & -0.92 & -1.91 \\
\hline 2 & $\begin{array}{c}\text { Standard } \\
\text { deviation of } \\
\text { skewness }\end{array}$ & 0.48 & \\
\hline 3 & $\begin{array}{c}\text { kurtosis } \\
\text { Standard of } \\
\text { deviation of } \\
\text { kurtosis }\end{array}$ & 0.83 & 0.88 \\
\hline
\end{tabular}

At the test level of $\alpha=0.05$, the skewness Z-score and kurtosis Z-score are within the variable range of \pm 1.96 . It is considered that the sample is subjected to normal distribution. 


\subsection{Normal distribution analysis}

The normal distribution $\mathrm{N}(\mu, \sigma 2)$ of measurement error data is analyzed.

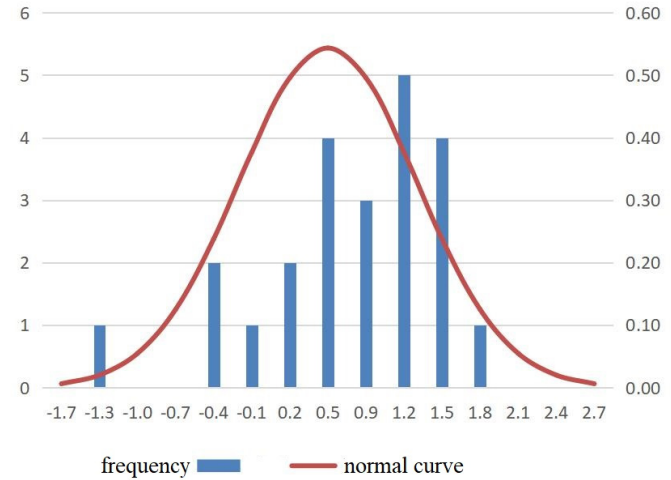

Fig.5 Azimuth measurement error normal distribution curve

According to the normal distribution, if the error data satisfies the normal distribution of $\mu=0.54$ and $\sigma=0.73$, the rule of thumb tells us that the probability of test error data in the range of $-0.19 \sim 1.27^{\circ}$ is $68.3 \%$.

\section{Technical application}

Along the Guoquan road station up and down the line 18 and the working station down the line 10 of Shanghai rail transit, due to the obstacles like underground diaphragm walls and piles, it is proposed to adopt the freezing method to reinforce the tunnel at the crossing section and then excavate the tunnel by the subsurface excavation method.

The length of the freezing drilling is 42 meters and the nearest distance between the drilling hole and the floor of the working station is 0.5 meters. As a result, the construction is difficult and requires high accuracy.

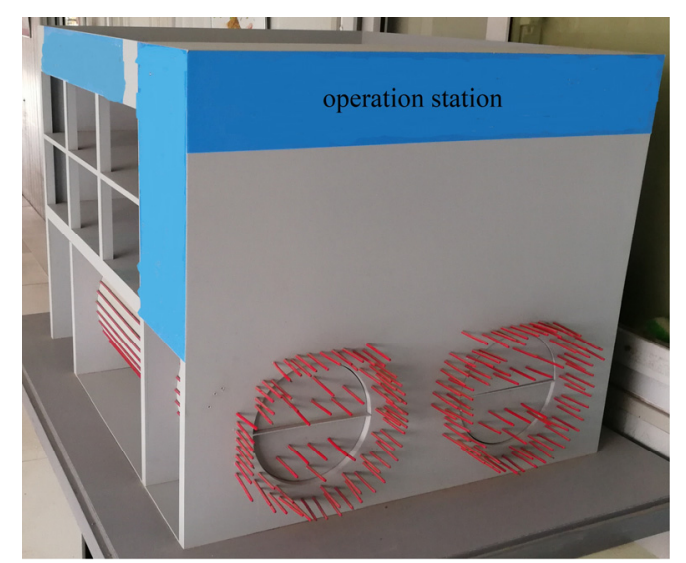

Fig.6 Drilling model of Guoquan road crossing engineering

Due to the long distance of the horizontal drilling, and since it needs to cross many complex obstacles during drilling, accurate detection of the deflection position of freezing holes is the key to the success of drilling and the need to ensure smooth closure. The application of the horizontal fiber-optical gyro inclinometer for the first time in the drilling of the freezing project at Guiuan road and the comparison between incline-measure data and incline-measure by light have again verified the accuracy of the horizontal fiber-optical gyro incline-measure.

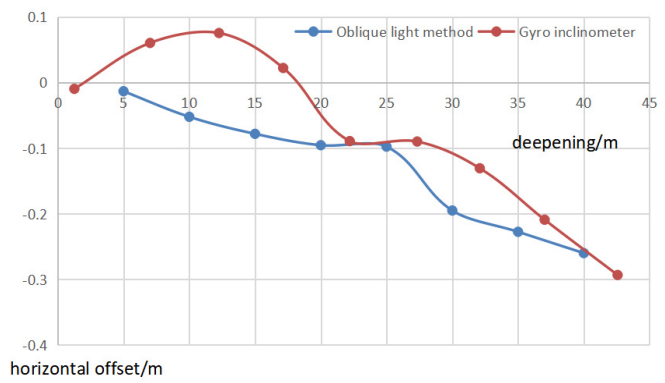

Fig.7 Comparison of the results of horizontal offset track measured by light method and gyroscope method ${ }^{6}$

From the comparative curve analysis of the horizontal offset (azimuthal measurement) of drilling tracks, it can be known that:

Using the incline-measure method by light and the horizontal fiber-optical gyro incline-measure method, it is found that the track trend is consistent in the horizontal direction and the maximum offset error is within 200 $\mathrm{mm}$.

\section{Conclusion}

(1) The first horizontal fiber-optical gyro inclinometer for the freezing hole was developed through the analysis based on the working conditions of the horizontal freezing hole inclinometer, the principle and advantages of the fiber-optical gyro inclinometer. And the field test was then conducted.

(2) By simulating the construction conditions, the ground test shows that for the data deviation of azimuthal angles in the freezing seamless steel pipe of the horizontal fiber-optical gyro inclinometer, the measurement error of $85.2 \%$ of the data is within the range of $\pm 2^{\circ}$, and that of $55.6 \%$ of the data is within the range of $\pm 1^{\circ}$.

(3) At the test level of $\alpha=0.05$, the measurement error data of azimuthal angles satisfies the normal distribution of $\mu=0.54$ and $\sigma=0.73$, and the probability of the measurement error of azimuthal angles in the range of $-0.19 \sim 1.27^{\circ}$ is $68.3 \%$.

(4) According to the field test results and the features of normal distribution, in the process of field measurement, we can try to calculate the mean value with repeated measurements for error optimization, making the measurement results approach the true value.

(5) The test results were successfully applied to the freezing hole incline-measure of the horizontal crossing freezing project at Guoquan road, and were compared with the data of the incline-measure by light, which further verified the reliability of the test results. The measurement error was within $200 \mathrm{~mm}$.

\section{Fund program :}

Science and technology innovation project of Tiandi 
technology Co., Ltd (2018-TD-QN010); Science and technology innovation project of Tiandi technology Co., Ltd（2018-TD-ZD004）。

\section{Introduction to the first author:}

JIANG Guojing (1987-), male, mainly engaged in freezing method and grouting method research and site management.

\section{References}

1. SUN Jun.Development and Some Issues on Exploitation and Utilization of Urban Underground space in China and Abroud[J]. Tunnel Construction, 2019,39(05):699-709.

2. CHEN Xiangsheng.The Current Situation and Construction Technology Innovation of Urban Underground Space in China. China Construction, 2019-09-13(006).

3. ZHU Hehua, DING Wenqi, QIAO Yafei, et al. Analysis of the problems and challenges in the development and utilization of urban underground space in China[J].Earth Science Frontiers, 2019, 26(03):22-31

4. CHEN Xiangsheng.Several Key Points of Artificial Ground Freezing and Its Latest Application in China[J]. Tunnel Construction, 2015, 35(12): 1243-1251.

5. LI Fangzheng.Application and Prospect of Municipal Freezing Technology[J]. Jingjing Technology, 2017,38(04):55-60+49.

6. ZHOU Xiaomin. Development of Artificial Ground Freezing Technology in Metro Tunnel Engineering[A]. China Civil Engineering Society. Underground Engineering Construction and Harmonious Development of Environment - The 4th China International Tunnel Engineering Symposium [C]. China Civil Engineering Society: Chinese Civil Engineering Engineering Society, 2009: 7.

7. WANG Shengli. Analysis and Application of Horizontal Freeze Drilling Trajectory of Subway Side Channel[J]. Construction Technology, 2009, 38(S1):76-78.

8. WANG Zhansheng,ZHANG Dingli.Key Techniques on Shallow Embedded Tunnel Constructed Beneath Existing Subway Tunnel[J].Chinese Journal of Rock Mechanics and Engineering,2007(S2):4208-4214.

9. Development and Application of Fiber Optic Gyro Inclinometer[J]. Geological equipment, 2012, 13(06): 20-23.

10. CHEN Haitao.Accuracy Analysis of the Results of Inertia Gyro in Non-excavation Pipeline Detection Engineering $[\mathrm{J}]$.Science \& Technology Innovation and Application,2019(19):67-69

11. XIAO Longxu,WANG Yan,CHEN Hengxuan,et al.The Inspection and Measurement of Inertial
Surveying System's Prelaunching Stability Based on Telemetry Data[J].Joural of Telemetry, Tracking and Command,2007(01):48-51.

12. Zhou Z, Tan Z, Wang X, et al. "Modified Dynamic North-Finding Scheme With a Fiber Optic Gyroscope," in IEEE Photonics Journal, vol. 10, no. 2, pp. 1-10, April 2018, Art no. 6801510.

13. Wang Q, Xie J, Yang C, et al. "Step angles to reduce the north-finding error caused by rate random walk with fiber optic gyroscope", Appl. Opt., vol. 54, no. 30, pp. 8944-8950, 2015.

14. ZHANG Wei,ZHANG Bowen,DAI Zhiguang,et al. Study on the response angular acceleration capability of high precision fiber optic gyroscope[J]. Command Control \& Simulation, 2019, 41(04): 130-134.

15. BI Junli, ZHANG Junfang. Study on the miniaturization technology of fiber optic gyroscope [J]. Digital Communication World, 2019 (05): 90-91.

16. JIANG Guojing,LI Fangzheng, ZHOU Xiaomin. Application of inclinometer technology of fiber optic gyroscope with near-horizontal freezing hole[J]. Tunnel Construction, 2020, 40(1):114. 